\title{
Comparison of The Effects of Several Feed Restriction Periods to Control Ascites on Performance, Carcass Characteristics and Hematological Indices of Broiler Chickens
}

Author(s)
Boostani $A^{1}$
Ashayerizadeh $A^{2}$
Mahmoodian Fard $\mathrm{HR}^{1}$
Kamalzadeh $\mathrm{A}^{3}$
1 Fars Education Center of Jahad-e-
Agriculture, Shiraz, Iran.
Department of Animal Science, Ramin
Agricultural and Natural Resources
University, Ahvaz, Iran.
Institute of Scientific and Applied Higher
Education of Jahad-e-Agriculture, Tehran,
Iran.

Mail Address

Amin Ashayerizadeh

Postal Address: No. 98, 8th Alley, Fazel Street, Sardkhaneh Avenue, Shiraz,

Iran. PC:7157858433

Tel: $+98-9173099064$

Fax: $+98-7297262150$

E-mail: amin.ashayerizadeh@yahoo.Com

\section{Keywords}

Ascites, broiler, feed restriction, hematological indices, performance.

\section{ABSTRACT}

This experiment was conducted to evaluate the effect of some feed restriction regimes on the performance, carcass characteristics and hematological values of broiler chickens. A number of 480 one-day-old Cobb broilers were distributed into 24 floor pens and reared for 42 days. A basal diet was formulated according to the NRC (1994) recommendations for starter (1-11 d), grower (12-28 d) and finisher ( $29-42 \mathrm{~d}$ ) periods. The restricted birds were fed $8 \mathrm{~h}$ per day from 7 to 21 $\left(R_{7-21 d}\right), 14$ to $28 d\left(R_{14-28 d}\right)$ or from 21 to $35 d\left(R_{21-35 d}\right)$, while the control birds were fed ad libitum. Birds and feed were weekly weighed, and dead birds were submitted to necropsy to determine the cause of death. At the end of experiment, blood samples were taken from 3 birds per pen, birds were weighed, and organ weights were recorded. All birds in the feed restriction treatments had lower body weight gain and feed intake than those fed ad libitum. Feed conversion ratio (FCR) was better in birds under $R_{7-21 d}$ as compared to the control group $(p<0.05)$. $R_{7-21 d}$ and $R_{14-28 d}$ birds presented lower general mortality and death due to ascites as compared to ad libitum-fed broilers. The birds under $R_{21-35 d}$ and $R_{14-28 d}$ treatments had lower breast weight and abdominal fat weight as compared to control birds, respectively $(p<0.05)$. A similar trend was observed for the percentage of the mentioned cuts. The right/total ventricular weight ratio (RV/TV) was significantly lower both in $R_{7-21 d}$ and $R_{14-28 d}$ treatments as compared to the control group. Blood constituents, such as glucose, cholesterol, and lactate dehydrogenase were also significantly altered by feeding regimes $(p<0.05)$. The results of present study showed that $\mathrm{R}_{7-21 d}$ reduced ascites incidence, but had no significant effect on growth performance.

\section{INTRODUCTION}

The ascites syndrome (ascites) is the primary cause of death for rapidly growing broiler strains, resulting in economic loss (Hassanzadeh et al., 2009). Ascites is a condition in which the body cavity accumulates serous fluid, leading to carcass condemnation or death (Julian, 1993). The causes of the syndrome are multifactorial and mainly induced by exogenous and/or endogenous factors. An imbalance between oxygen supply and the oxygen required to sustain rapid growth rates and high food efficiencies is believed to be the primary cause of ascites in broiler chickens (Decuypere et al., 2000 \& 2005; Julian, 2005). The housing environment, including factors such as temperature (cold or fluctuating temperatures) and air quality (dust concentration, carbon dioxide levels, and oxygen levels), is known to influence the incidence of ascites in broiler chickens. The incidence of ascites greatly increases at altitudes greater than 1300 meters above sea level, presumably because of the low oxygen partial pressure (Hernandez, 1987). Physiologically, low 
oxygen $\left(\mathrm{O}_{2}\right)$ concentration creates an oxygen deficit (hypoxia) and a demand for more oxygen. The increased demand may exceed the cardiopulmonary capacity to supply sufficient oxygen, resulting in pulmonary hypertension and right ventricular failure (Julian, 1993). The peak of ascites incidence occurs in weeks 5-6 of the growing period, but it is thought that the etiology of the syndrome is initiated much earlier, even during the embryonic stage (Coleman \& Coleman, 1991). Feed restriction is becoming a common treatment employed to reduce the incidence of ascites in broilers and roasters under commercial conditions (Arce et al., 1992; Acar et al., 1995). Research has shown that feed restriction timing, duration, and severity have an impact on whether a bird is capable of achieving the same body weight as unrestricted birds (Ballay et al., 1992; Yu \& Robinson, 1992). Early feed restriction regimes for broiler chickens have been previously researched (Mollison et al., 1984; Summers et al., 1990; Wall et al., 1999; Bhat \& Banday, 2000; Lee \& Leeson, 2001). The benefits of early feed restriction are the monetary savings obtained by improved feed conversion (Proudfoot et al., 1983), reduced sudden death syndrome (Mollison et al., 1984; Bhat \& Banday, 2000), reduced death losses (Tottori et al., 1997), reduced ascites (Arce et al., 1992) and reduced skeletal disease (Robinson et al., 1992). Not only the early feed restriction regimes, but also the late feed restriction or feed withdrawal regimes before four to five weeks of age may reduce the incidence and severity of ascites. Therefore, the objectives of the study were to evaluate the effects of early and late feed restriction on broiler growth performance, carcass characteristics, ascites syndrome incidence, and changes in blood constituents.

\section{MATERIALS AND METHODS}

\section{Birds and housing}

One-day-old male broilers of a commercial strain (Cobb), obtained from a commercial hatchery, were kept on floor pens and fed ad libitum with a pelleted commercial broiler starter diet until 7 days of age. At this age, 480 broiler chicks were individually weighed to obtain similar pen weights, and randomly assigned to one of four treatments, with six replicates of 20 chicks each. The chicks were placed at simulated 1890 m (6,200 ft) above sea level and housed in 24 floor pens covered with $10-\mathrm{cm}$ deep, clean wood shavings after 7 days of age. In order to increase probability of ascites incidence, a cold stress temperature schedule was applied. All birds were brooded under about 35 ${ }^{\circ} \mathrm{C}$ from 1 to $7 \mathrm{~d}$ of age, then $30^{\circ} \mathrm{C}$ from 8 to $14 \mathrm{~d}$. Thereafter, birds were subjected to a step-down temperature program of 1 to $2{ }^{\circ} \mathrm{C}$ per day down until 12 to $14{ }^{\circ} \mathrm{C}$, where it remained constant until the end of the experiment. A continuous lighting program was provided for all treatment groups during the experiment.

\section{Diets}

Birds were fed commercial corn-soybean pelleted broiler starter, grower and finisher diets, formulated to meet or exceed minimum NRC (1994) standards for all ingredients. All birds received a starter diet from 1 to $11 \mathrm{~d}$. The grower and finisher diets were provided from 12 to $28 \mathrm{~d}$ and 29 to $42 \mathrm{~d}$ of age, respectively. The compositions of the diets are shown in Table 1.

\begin{tabular}{lrrr}
\hline \multicolumn{4}{l}{ Table 1 - Ingredient composition (as percent of dry matter) and } \\
calculated analysis of the basal diets. & & \\
Ingredients & Starter & Grower & Finisher \\
Yellow corn & 495.3 & 530.4 & 536.4 \\
Soybian meal(44\%) & 383.1 & 315.1 & 300.2 \\
Wheat grain & 50.2 & 80 & 100 \\
Fish meal (66\%) & 25 & 25 & 0 \\
Vegetable oil & 10.3 & 16 & 28 \\
Dicalcium phosphate & 15.3 & 14.4 & 15.2 \\
Oyster shell & 9.5 & 8.4 & 10.2 \\
Salt & 1.5 & 1.4 & 1.8 \\
Vitamin-mineral premix & 6 & 5.5 & 5 \\
Coccidiostat & 0.4 & 0.4 & 0.4 \\
DL- Methionine & 2.3 & 2.2 & 2 \\
L-Lysine & 1.1 & 1.2 & 0.8 \\
Calculated chemical composition & 12.14 & 12.56 & 12.97 \\
ME (MJ/kg) & 22.2 & 20.2 & 18.2 \\
Crude protein (\%) & 1 & 0.97 & 0.92 \\
Calcium (\%) & 0.5 & 0.48 & 0.45 \\
Available phosphorus (\%) & & \\
\hline
\end{tabular}

1 - vitamin and mineral provided per kilogram of diet: vitamin A, $360000 \mathrm{IU}$; vitamin D3, $800000 \mathrm{IU}$; vitamin E, $7200 \mathrm{IU}$; vitamin K3, 800 mg; vitamin B1, 720 mg; vitamin B9, 400 mg; vitamin H2, 40 mg; vitamin B2, 2640 mg, vitamin B3, 4000 mg; vitamin B5, 12000 mg; vitamin B6, 1200 mg; vitamin B12, 6 mg; Choline chloraid, 200000 mg, Manganeze, 40000 mg, Iron, 20000 mg; Zinc, 40000 mg, coper, 4000mg; lodine, 400 mg; Selenium, 80 mg.

\section{Feed restriction program}

Three quantitative feed restriction programs were applied at different ages. Broilers on treatment $R_{7-21 d}$ had feed available for $8 \mathrm{~h}$ daily for 2 weeks, from $\mathrm{d} 7$ to 21 , and then received ad libitum feed for the remaining 3 weeks. Broilers on treatment $R_{14-28 d}$ were fed $8 \mathrm{~h}$ daily from $\mathrm{d} 14$ to 28 , then returned to ad libitum feeding. Treatment $R_{21-35 d}$ were fed ad libitum for the first 3 weeks, had $8 \mathrm{~h}$ feed availability for the next 2 weeks, and then fed ad libitum for the remaining 1 
week. The controls were given ad libitum access to feed throughout rearing.

\section{Variables measured}

Body weight and feed consumption were weekly measured per pen. Feed conversion ratio was calculated on pen basis. The incidence of ascites, death due to ascites, and overall mortality rate were determined at 7 and 42 days of age and calculated as percentage of total birds in each treatment. Incidence of ascites (non-fatal) was determined by physical examination. However, all dead birds were autopsied to determine if the cause of death was ascites. Birds that exhibited marked hypertrophy in the right ventricle and the pericardium filled with fluid were identified as dead due to ascites. Birds with severe or less severe ascites syndrome were identified to calculate the incidence of ascites. At the end of the experimental period, $4 \mathrm{ml}$ of blood was collected from wing vein from 18 birds in each treatment. In order to prevent clotting, blood was collected in heparinized test tubes and centrifuged (at 2,000 rpm for $10 \mathrm{~min}$ ), and the serum was separated, then stored at $-20^{\circ} \mathrm{C}$ until assayed to measure blood parameters (glucose, total protein, albumin, cholesterol, and lactate dehydrogenase) using appropriate laboratory kits (Gordon et al., 1977; Gowenlock et al, 1988). Hematocrit was measured using microhaematocrit (Safamehr, 2008) and activity of serum lactate dehydrogenase was measured by a spectrophotometric method (Mc Comb et al., 1976 ). Serum globulin was calculated by subtracting serum albumin from total serum protein levels. Birds were then weighed and slaughtered for carcass evaluation (Perreault \& Leeson, 1992). Carcass, breast, heart, and abdominal fat were individually weighed and expressed as a percentage of live body weight. Hearts were dissected and, after careful removal of the atria, right ventricle (RV) and total ventricle (TV) were weighed to calculate RV/TV weight ratio, which is considered as an index of ascites (Julian, 1993; Lubritz et al., 1995).

\section{Statistical analysis}

All data were submitted to analysis of variance using the One-Way Anova procedure of $\operatorname{SAS}^{\circledR}$ (SAS, 1998). Differences among treatments were determined as significant at $5 \%$ level by Duncan's multiple range tests (Duncan, 1955).

\section{RESULTS AND DISCUSSION}

\section{Growth performance and mortality}

The effects of feed restriction regimes on performance and mortality are presented in Table 2 . The control group presented significantly higher performance than the $R_{14-28 d}$ and $R_{21-35 d}$ groups. Feed consumption was significantly reduced by feed restriction regimes $(p>0.05)$. Feed conversion was improved in all restricted-fed groups, although this differences was significant $(p<0.05)$ only when the control group was compared to the $R_{7-21 d}$ treatment. Both $R_{7-21 d}$ and $R_{14-28 d}$ regimes significantly decreased the incidence of ascites, mortality, and death due to ascites. Also, there was a significant difference between $R_{7-21 d}$ and $R_{14-28 d}$ in death due to ascites rate.

Similar observations were reported for body weight gain of birds under $R_{7-8 d}$ and $R_{21-35 d}$ by Balog et al, (2000) and Camacho et al, (2004), respectively. On the other hand, our findings for body weight gain of birds under $\mathrm{R}_{7-21 d}$ contrast with those of Pan et al. (2005). It seems that the birds restricted-fed from 14 to $28 \mathrm{~d}$ or 21 to $35 \mathrm{~d}$ of age did not present sufficient compensatory growth to achieve the same final body weight of the control group. As a result, the age of birds at the beginning of the restriction period had an important effect on compensatory growth rate. Plavnik \& Hurwitz (1990) tested the effect of age on the response of male chicks to feed restriction. Restriction started at 3, 5, or $7 \mathrm{~d}$ of age, and feed intake was significantly reduced by feed restriction, without any difference due to age. However, the present study shown that feed intake following feed restriction from 21 to $35 \mathrm{~d}$ was significantly reduced. Also, our findings for FCR of R7$21 \mathrm{~d}$ group are consistent with those of Pan et al, (2005),

\begin{tabular}{|c|c|c|c|c|c|}
\hline \multirow[b]{2}{*}{ Variables } & \multicolumn{4}{|c|}{ Treatments } & \multirow[b]{2}{*}{ SEM } \\
\hline & Control & $R^{7-519}$ & $R_{14-28 d}$ & $R_{21-35 d}$ & \\
\hline Body weight gain (g) & $2286.14 a$ & $2224.09 a b$ & $2171.73 b$ & $2161.42 b$ & 36.49 \\
\hline Feed consumption $(\mathrm{g})$ & $4558.34 \mathrm{a}$ & $4302.42 \mathrm{~b}$ & $4254.93 b$ & $4237.56 \mathrm{~b}$ & 43.13 \\
\hline Feed conversion ratio (g g-1) & $1.99 a$ & $1.93 b$ & $1.95 a b$ & $1.96 a b$ & 0.01 \\
\hline Mortality (\%) & $12.50 \mathrm{a}$ & $4.16 b$ & $5.83 \mathrm{~b}$ & $9.16 \mathrm{ab}$ & 1.82 \\
\hline Death due to ascites (\%) & $10.83 a$ & $4.16 b$ & $5.00 \mathrm{~b}$ & $7.50 \mathrm{ab}$ & 1.77 \\
\hline Incidence of ascites (\%) & $17.50 \mathrm{a}$ & $8.33 b c$ & $6.66 \mathrm{c}$ & $13.33 \mathrm{ab}$ & 1.79 \\
\hline
\end{tabular}

$a, b$ - means in each column with different superscripts are significantly different $(p<0.05)$. 
whi reported that cumulative FCR between $d 7$ and d 49 was not significantly affected by feed restriction.

It is known that early feed restriction reduces the incidence of ascites, mortality, and death due to ascites (Leeson et al., 1992; Acar et al., 1995; Balog et al., 2000; Camacho et al., 2004; Pan et al., 2005). A similar result was obtained in the present study. Although the birds in the $\mathrm{R}_{7-21 \mathrm{~d}}$ group followed a similar trend, there were no significant differences as compared to the control group. In the present study, out of the 480 broilers used, 38 died between 7 and 42 days of age. A total of 33 broilers died due to ascites in all treatment groups.

\section{Carcass composition}

The effect of the experimental treatments on the carcass weight (both in terms of absolute value and percentage of body weight) and RV/TV ratio are given in Table 3. Carcass weight and breast weight and yield of birds under $R_{21-35 d}$ treatment were significantly lower as compared to those of control treatment $(p<0.05)$. Mean abdominal fat weight and yield of $R_{21-35 d}$ birds was lower as compared to the control treatment $(p<0.05)$. RV weight and RV/TV values obtained with $\mathrm{R}_{7-21 \mathrm{~d}}$ and $\mathrm{R}_{14-28 \mathrm{~d}}$ treatments were lower than those of birds fed ad libitum $(p<0.05)$. Carcass weight and heart weight and yield did not differ among treatments (p>0.05).

However, our carcass weight findings in birds under the $R_{21-35 d}$ treatment was in contrast to those of Camacho et al. (2004). The results abdominal fat content of treatments $R_{7-21 d}$ and $R_{21-35 d}$ support the recent findings of Summers et al. (1990), Yu et al. (1990), and Fontana et al. (1993), who observed no differences in abdominal fat pad weight between ad libitum and feed-restricted broilers during the restriction period. Contrary to these findings, Plavnik et al. (1986), Rosebrough et al. (1986), Acar et al. (1995), and Saleh et al. (1996) determined that feed restriction reduced abdominal fat pad weight, which is in agreement with our finding for the $R_{14-28 d}$ group. According to the study of Rosebrough et al. (1986), the activities of lipogenic enzymes were depressed during the period of feed restriction, peaked in the first week of refeeding, and gradually declined to below those of the control birds in the subsequent weeks. The differences in these findings may be due to the differences in treatments, time of feed restriction, sex, strains, or duration of feed restriction. The percentage of total heart relative to body weight at 42 days of age was also not statistically affected by the feeding restriction regimes. This is consistent with the results of Acar et al. (1995). Also in the present study, the negative effect of feed restriction on breast yield was in contrast with those reported by Camacho et al. (2004). Before a bird exhibits gross ascites syndrome lesions, hematological and anatomical changes can be detected (Maxwell et al., 1986; 1987). An increase in RV/TV ratio indicates the onset of pulmonary hypertension and ascites syndrome (Burton et al., 1968; Cueva et al., 1974; Huchzermeyer \& DeRuyck, 1986; Hernandez, 1987). It is generally accepted that an RV/TV index greater than 0.30 is indicative of right ventricular hypertrophy, pulmonary hypertension and, ultimately, ascites syndrome (Cueva et al., 1974; Hernandez, 1987; Huchzermeyer et al., 1988; Wideman et al., 1998). In contrast to our findings, Balog et al., (2000) reported that the RV/TV ratio was not increased in restricted-fed birds at hypobaric altitude.

\begin{tabular}{|c|c|c|c|c|c|}
\hline \multirow[b]{2}{*}{ Variables } & \multicolumn{4}{|c|}{ Treatments } & \multirow[b]{2}{*}{ SEM } \\
\hline & Control & $R_{7-21 d}$ & $R_{14-28 d}$ & $R_{21-35 d}$ & \\
\hline \multicolumn{6}{|l|}{ As gram } \\
\hline Carcass & $1994.22 \mathrm{a}$ & 1996.74 a & $1928.62 a b$ & $1895.40 \mathrm{~b}$ & 30.95 \\
\hline Breast & $645.39 a$ & $609.92 \mathrm{ab}$ & $589.39 a b$ & $562.65 \mathrm{~b}$ & 19.85 \\
\hline Abdominal fat & $44.68 \mathrm{a}$ & $39.94 a b$ & $35.45 b$ & $37.33 a b$ & 2.49 \\
\hline Heart & $9.51 \mathrm{a}$ & $9.30 \mathrm{a}$ & $8.77 \mathrm{a}$ & 8.89 a & 0.46 \\
\hline $\mathrm{TV}^{1}$ & $7.56 \mathrm{a}$ & $7.39 \mathrm{a}$ & $7.38 \mathrm{a}$ & $7.38 \mathrm{a}$ & 0.13 \\
\hline $\mathrm{RV}^{2}$ & $1.99 \mathrm{a}$ & $1.82 \mathrm{~b}$ & $1.80 \mathrm{~b}$ & $1.87 \mathrm{ab}$ & 0.03 \\
\hline \multicolumn{6}{|l|}{ As $\%$} \\
\hline Carcass & $79.67 \mathrm{a}$ & 80.33 a & 79.45 a & $77.89 a$ & 1.14 \\
\hline Breast & $25.77 \mathrm{a}$ & $24.50 \mathrm{ab}$ & $24.28 \mathrm{ab}$ & $23.145 \mathrm{~b}$ & 0.76 \\
\hline Abdominal fat & $1.78 \mathrm{a}$ & $1.60 \mathrm{ab}$ & $1.45 \mathrm{~b}$ & $1.53 \mathrm{ab}$ & 0.09 \\
\hline Heart & $0.38 \mathrm{a}$ & $0.37 \mathrm{a}$ & $0.36 a$ & 0.36 a & 0.01 \\
\hline TV & $0.303 \mathrm{a}$ & $0.298 a$ & 0.305 a & 0.303 a & 0.01 \\
\hline RV & $0.080 \mathrm{a}$ & $0.073 \mathrm{~b}$ & $0.075 a b$ & $0.076 \mathrm{ab}$ & 0.01 \\
\hline $\mathrm{RV} / \mathrm{TV}$ & $26.35 \mathrm{a}$ & $24.65 b$ & $24.46 b$ & $25.32 \mathrm{ab}$ & 0.74 \\
\hline
\end{tabular}

$a, b$ - means in each column with different superscripts are significantly different $(p<0.05) .1 \mathrm{TV}=$ Total Ventricular, 2RV= Right Ventricular. 


\section{Blood constituents}

The effect of feed restriction on blood constituents is presented in Table 4. No significant differences were observed in total protein, albumin, or globulin levels among treatments. Broilers under the $\mathrm{R}_{21-35 \mathrm{~d}}$ treatment had significantly higher blood glucose levels than broilers in group $R_{7-21 d}$ and control group $(p<0.05)$. Lactate dehydrogenase levels for $R_{21-35 d}$ and $R_{14-28 d}$ broilers were significantly higher than in control broilers. $R_{21-35 d}$ regime caused a significant decrease in hematocrit value as compared to full-fed broilers. Serum cholesterol concentrations of $R_{14-28 d}$ and $R_{21-35 d}$ treatments were lower than those of control birds $(p<0.05)$.

Blood parameters findings in this experiment, except for cholesterol and albumin, support previous findings (Balog et al., 2004; Demir et al., 2004). Also, serum cholesterol data are not in agreement with the data of Church \& Pond (1988), who indicated that meal-fed or starved chickens have been shown to have higher plasma cholesterol than control birds. The higher levels of serum glucose in restricted-fed birds may be due to better FCR and nutrient absorption. However, Riesenfeld et al. (1982) and Klasing (1998) have reported that chickens maintain a steady glucose level during fasting. Hypoglycemia during fasting is prevented by glucose synthesis via gluconeogenesis. Lactate is produced from glucose by the intestine and up to $37 \%$ of the glucose taken up from the intestinal lumen may be converted into lactate before being transferred to the circulation (Riesenfeld et al., 1982). Lactate dehydrogenase is responsible for converting pyruvate into lactate, and therefore, the high levels of glucose in $R_{21-35 d}$ and $R_{14-28 d}$ broilers may have caused an increase in the blood lactate dehydrogenase levels. Hematocrit is another common measure of ascites development (Burton \& Smith, 1967; Maxwell, 1991; Mirsalimi \& Julian, 1991; Yersin et al., 1992; Fedde \& Wideman, 1996). As expected, broilers fed ad libitum had a higher hematocrit values due to their higher growth rate and oxygen requirement. According to the results, it is probable that if the restricted-fed birds had been allowed to continue full feed for several more weeks, their hematocrit values would have approached those of the fully fed controls.

\section{CONCLUSION}

The results of this study showed that the age at which feed restriction regime is applied is an important factor to control mortality from ascites and to allow compensatory growth of the restricted-fed chickens. According to the results of performance and ascites indexes the $R_{7-21 d}$ and $R_{14-28 d}$ treatments were more effective to reduce ascites problems.

\section{REFERENCES}

Acar N, Sizemore FG, Leach GR, Wideman RF, Owen JRL, Barbato GF. Growth of broiler chickens in response to feed restriction regimes to reduce ascites. Poultry Science 1995; 74:833-843.

Acar N, Sizemore FG, Leach GR, Wideman RF, Owen RL, Barbato GF. Growth of broiler chickens in response to feed restriction regimens to reduce ascites. Poultry Science 1995; 74:833-843.

Arce J, Berger M, Coello CL. Control of ascites syndrome by feed restriction techniques. Journal of Applied Poultry Research 1992; $1: 1-5$

Ballay ME, Dunnington A, Gross WB, Siegel PB. Restricted feeding and broiler performance: Age at initiation and length of restriction. Poultry Science 1992; 71:440-447.

Balog JM, Anthony NB, Cooper MA, Kidd BD, Huff GR, Huff WE, Rath NC. Ascites syndrome and related pathologies in feed restricted broilers raised in a hypobaric chamber. Poultry Science 2000; 79: 318-323.

Bhat GA, Banday MT. Effect of feed restriction on the performance of broiler chickens during the winter season. Indian Journal of Poultry Science 2000; 35:112-114.

Burton RR, Smith AH. The effect of polycythemia and chronic hypoxia on heart mass in the chicken. Journal of Applied Physiology 1967; 22:782-785.

\begin{tabular}{|c|c|c|c|c|c|}
\hline \multirow[b]{2}{*}{ Parameters } & \multicolumn{4}{|c|}{ Treatments } & \multirow[b]{2}{*}{ SEM } \\
\hline & Control & $R_{7-21 d}$ & $\mathbf{R}_{14-28 \mathrm{~d}}$ & $\mathbf{R}_{21-35 \mathrm{~d}}$ & \\
\hline Glucose (mg dl-1) & $213.66 b$ & $213.50 \mathrm{~b}$ & $217.50 \mathrm{ab}$ & $224.83 \mathrm{a}$ & 2.70 \\
\hline Total protein (g dl-1) & 3.89 a & $3.76 \mathrm{a}$ & $3.80 \mathrm{a}$ & $3.84 \mathrm{a}$ & 0.18 \\
\hline Albumin (g dl-1) & $1.78 \mathrm{a}$ & $1.74 \mathrm{a}$ & $1.80 \mathrm{a}$ & $1.74 \mathrm{a}$ & 0.14 \\
\hline Globulin (g dl-1) & $2.10 a$ & $2.02 a$ & $1.99 a$ & $2.09 a$ & 0.12 \\
\hline Cholesterol (g dl-1) & $165.73 \mathrm{a}$ & $159.13 a b$ & $143.55 \mathrm{~b}$ & $146.10 \mathrm{~b}$ & 6.03 \\
\hline Hematocrit (\%) & 31.10 a & $30.67 \mathrm{ab}$ & $30.07 a b$ & $29.76 b$ & 0.37 \\
\hline lactate dehydrogenase & -1)487.06 b & $540.70 a b$ & $553.20 \mathrm{a}$ & $556.08 \mathrm{a}$ & 18.80 \\
\hline
\end{tabular}

$a, b$ - means in each column with different superscripts are significantly different $(p<0.05)$. 
Burton RR, Besch EL, Smith AH. Effect of chronic hypoxia on the pulmonary arterial blood pressure of the chicken. American Journal of Physiology 1968; 14:1438-1442.

Camacho MA, Suarez ME, Herrera JG, Cuca JM, Garcia-Bojalil CM. Effect of age of feed restriction and microelement supplementation to control ascites on production and carcass characteristics of broilers. Poultry Science 2004; 83:526-532.

Church DC, Pond WG. Basic animal nutrition and feeding. New York,USA: John Wiley and Sons Press; 1998.

Coleman MA, Coleman GE. Ascites control through proper hatchery management. Misset World Poultry 1991; 145:166-175.

Cueva S, Sillau H, Valenzuela A, Ploog H. High altitude induced pulmonary hypertension and right heart failure in broiler chickens. Research in Veterinary Science 1974; 16:370-374.

Decuypere E, Buyse J, Buys N. Ascites in broiler chickens: exogenous and endogenous structural and functional causal factors. World's Poultry Science Journal 2000; 56:367-376.

Decuypere E, Hassanzadeh M, Buys B, Buyse J. Further insights insights into the susceptibility of ascites. The Veterinary Journal 2005; 169:319-320.

Duncan DB. Multiple range test and multiple F-tests. Biometrics 1955; 11:1-42.

Fedde MR, Wideman RF. Blood viscosity in broilers: influence on pulmonary hypertension syndrome. Poultry Science 1996; 75:12611267.

Fontana EA, Weaver WD, Denbow DM. Watkins BA. Early feed restriction of broilers: Effects on abdominal fat pad, liver, and gizzard weights, fat deposition and carcass composition. Poultry Science 1993; 72:243-250.

Gordon T, Castelli WP, Hjortland MC, Kannel WB, Dawber TR. High density lipoprotein as a protective factor against coronary heart disease: the framingham study. American Journal of Medicine 1977; 62:707-714.

Gowenlock AH, McMurray JR, McLauchlan DM. Varley's Practical clinical biochemistry. 6th ed. New Delhi: CAS Publishers and Distributors; 1988. p.477-549.

Hassanzadeh M. New approach for the incidence of ascites syndrome in broiler chickens and management control the metabolic disorders. International Journal of Poultry Science 2009; 8(1):90-98.

Hernandez A. Hypoxic ascites in broilers: A review of several studies done in Colombia. Avian Diseases 1987; 31:658- 661.

Huchzermeyer FW, DeRuyck AMC. Pulmonary hypertension syndrome associated with ascites in broilers. The Veterinary Record 1986; $119: 94$.

Huchzermeyer FW, DeRuyck AMC, VanArk H. Broiler pulmonary hypertension syndrome. III. Commercial broiler strains differ in their susceptibility. Onderstepoort Journal of Veterinary Research 1988; 55:5-9.

Julian RJ. Ascites in poultry. Avian Pathology 1993; 22:419- 454.

Julian RJ. Production and growth related disorders and other metabolic disease of poultry- A review. The Veterinary Journal 2005; 169:350-369.

Klasing KC. Comparative avian nutrition. New York (USA): Cab International Press; 1998.

Lee $\mathrm{KH}$, Leeson S. Performance of broilers fed limited quantities of feed or nutrients from 7 to 14 days of age. Poultry Science 2001; 80:446-454.

Leeson S, Sumrners JD, Caston LJ. Response of broilers to feed restriction or diet dilution in the finïsher period. Poultiy Science 1992; 71:2056-2064.

Lubritz DL, Smith L, Mcpherson BN. Heritability of ascites and the ratio of right to total ventricle weight in broiler breeder male lines. Poultry Science 1995; 74:1237-1241.

Maxwell MH. Red cell size and various lung arterial measurements in different strains of domestic fowl. Research in Veterinary Science $1991 ; 50: 233-239$

Maxwell MH, Robertson GW, Spence S. Studies on an ascitic syndrome in young broilers 1. Haematology and pathology. Avian Pathology 1986; 15:511-524.

Maxwell MH, Tullet SG, Burton FG. Haematology and morphological changes in young broiler chicks with experimentally induced hypoxia. Research in Veterinary Science 1987; 43:331-338.

McComb RB, Bond LW, Burnett RW. Determination of the molar absorptivity of NADH. Clinical Chemistry 1976; 22:141-150.

Mirsalimi SM, Julian RJ. Reducing erythrocyte deformability as a possible contributing factor to pulmonary hypertension and ascites in broiler chickens. Avian Diseases 1991; 35:374-379.

Mollison B, Guenter W, Boyctt BR. Abdominal fat deposition and sudden death syndrome in broilers: the effects of restricted intake, early life caloric (fat) restriction and calorie: protein ratio. Poultry Science 1984; 63:1190-1200.

NRC - National Research Council, Nutrient requirements of poultry. 9th ed. Washington (DC): National Academy Press; 1994.

Pan JQ, Tan X, Li JC, Sun WD, Wang XL. Effects of early feed restriction and cold temperature on lipid peroxidation, pulmonary vascular remodelling and ascites morbidity in broilers under normal and cold temperature. British Poultry Science 2005; 46:374-381.

Perreault N, Leeson S. Age-related carcass composition changes in male broiler chickens. Canadian Journal of Animal Science 1992; 72:919-929.

Plavnik I, Hurwitz S. Performance of broiler chickens and turkey poults subjected to feed restriction or to feeduig of low-protein or lowsodium diets at an early age. Poultry Science 1990; 69:945-952. 
Plavnik I, McMurty JP, Rosebrough RW. Effect of early feed restriction in broilers. I. Growth performance and carcass composition. Growth 1986; 50:68-76.

Proudfoot FG, Hulan HW, McRae KB. The effect of feed denial in starter diets on the performance of broiler chickens. Poultry Science 1983; 62:1915-1917.

Riesenfeld G, Geva A, Hurwitz S. Glucose homeostasis in the chicken. Journal of Nutrition 1982; 112:2261-2266.

Robinson FE, Classen HL, Hanson JA, Onderka DK. Growth performance, feed efficiency and the incidence of skeletal and metabolic disease in ad libitum and feed restricted broiler and roaster chickens. Journal of Applied Poultry Research 1992; 1:3341.

Rosebrough RW, Steele NC, McMurty JP, Plavnik I. Effect of early feed restriction in broilers. II. Lipid metabolism. Growth 1986; 50:217-227.

Safamehr A. The performance and hematological characters in broilers chicks fed ammonia- treated alfatoxin contaminated feed. Journal of animal and veterinary advances 2008; 7(3):331-336.

Saleh K, Attia YA, Younis H. Effect of feed restriction and breed on compensatory growth, abdominal fat and some production traits of broiler chicks. Archiv flir GeflUgelkunde 1996; 60:153-159.

Statistic Analysis System. Painless windows, a handbook for SAS users. 2nd ed. Guelph ON: Jodie Gilmore; 1998.

Summers JD, Spratt D, Atkinson JL. Restricted feeding and compensatory growth for broilers. Poultry Science 1990; 69:225229.

Tottori J, Yamaguchi R, Murakawa Y, Sato M, Uchida K, Tateyawa S. The use of feed restriction for mortality control of chickens in broiler farms. Avian Diseases 1997; 41:433-437.

Wall PG, van der Reimert HGM, Goedhart HA, Engel B. Uijttenboogaardt TG. The effect of feed withdrawal on broiler blood glucose and non-esterified fatty acid levels, postmortem liver $\mathrm{pH}$ values, and carcass yield. Poultry Science 1999; 78:569-573.

Wideman RF, Wing T Jr, Kirby YK, Forman MF, Marson N, Tackett $C D$, Ruiz-Feria CA. Evaluation of minimally invasive indices for predicting ascites susceptibility in three successive hatches of broilers exposed to cool temperatures. Poultry Science 1998; 77:1565-1573.

Yersin AG, Huff WE, Kubena LF, Elissalde MA, Harvey RB, Witzel DA, Giroir LE. Changes in hematological, blood gas, and serum biochemical variables in broilers during exposure to simulated high altitude. Avian Diseases 1992; 36:189-197.

Yu ME, Robinson EE, Clandinin MT, Bodnar L. Growth and body composition of broiler chickens in response to different regimes of feed restriction. Poultry Science 1990; 69:2074-2081.

Yu MW, Robinson FE. The application of short-term feed restriction to broiler chicken production: A review. The Journal of Applied Poultry Research 1992; 1:147-153. 